\title{
Natapiane i natryskane cieplnie powłoki Ni-Cr-B-Si
}

\author{
The Ni-Cr-B-Si coatings obtained in surfacing \\ and thermal spraying processes
}

\section{Streszczenie}

Artykuł dotyczy wybranych metod wytwarzania powłok Ni-Cr-B-Si. W pracy opisano natapianie w piecu próżniowym oraz naddźwiękowe natryskiwanie płomieniowe (HVOF). Przeprowadzono próby natapiania i natryskiwania, wykonano badania mikroskopowe oraz pomiary twardości powierzchniowej otrzymanych powłok. Zastosowane metody pozwalają na uzyskanie wielofazowej powłoki o wysokiej twardości.

Słowa kluczowe: natapianie; natryskiwanie cieplne; metoda HVOF; powłoka Ni-Cr-B-Si

\section{Abstract}

This paper covers the selected methods of manufacturing the Ni-Cr-B-Si coatings. It describes the surfacing process in the vacuum furnace and the high velocity oxy fuel thermal spraying (HVOF). The surfacing and thermal spraying processes were carried out. The paper presents results of the microscopic research and the surface hardness measurements of the obtained coatings. Applied methods allow for achieving a multiphase coating with high hardness.

Keywords: surfacing; thermal spraying; HVOF method; Ni-CrB-Si coating

\section{Wstęp}

Trwałości eksploatacyjną części i elementów maszyn można podnieść w znaczący sposób za pomocą wytwarzania warstw i powłok, które korzystnie zmieniają właściwości powierzchniowe oraz zabezpieczają rdzeń elementu przed szkodliwym działaniem środowiska. Do wytwarzania warstw i powłok odpornych na zużycie ścierne służą na ogół stopy na bazie żelaza, kobaltu i niklu [1].

Stopy Ni-Cr-B-Si znajdują zastosowanie jako materiał do wytwarzania warstw i powłok, głównie poprzez napawanie lub natryskiwanie cieplne. Stosuje się je jako pokrycia narzędzi i elementów maszyn przeznaczonych do produkcji m.in. szkła, ceramiki, cementu oraz stali [2]

Powłoki Ni-Cr-B-Si charakteryzują się wysoką odpornością na zużycie ścierne, odpornością na działanie wysokiej temperatury oraz odpornością na korozję. Dobre właściwości tych powłok wynikają z mikrostruktury po krystalizacji. W większości stopów z tej grupy tworzą się fazy borków niklu oraz chromu, które umacniają niklową osnowę. Stosunek ilości twardych faz do plastycznej osnowy powinien być dobrany zgodnie z przeznaczeniem powłoki, np. dla powłok pracujących na zużycie ścierne powinien on być wyższy, niż dla powłok żaroodpornych $[1 \div 3]$.

\section{Natapianie w piecu próżniowym}

Natapianie polega na nakładaniu stopionego materiału powłokowego na podłoże w stanie stałym. Zjawiska fizyczne i fizykochemiczne podczas natapiania są zbliżone do lutowania. Proces można prowadzić z wykorzystaniem różnych źródeł ciepła, np. stosując urządzenia spawalnicze, piece atmosferowe lub próżniowe. Schemat natapiania przedstawiono na rysunku 1.
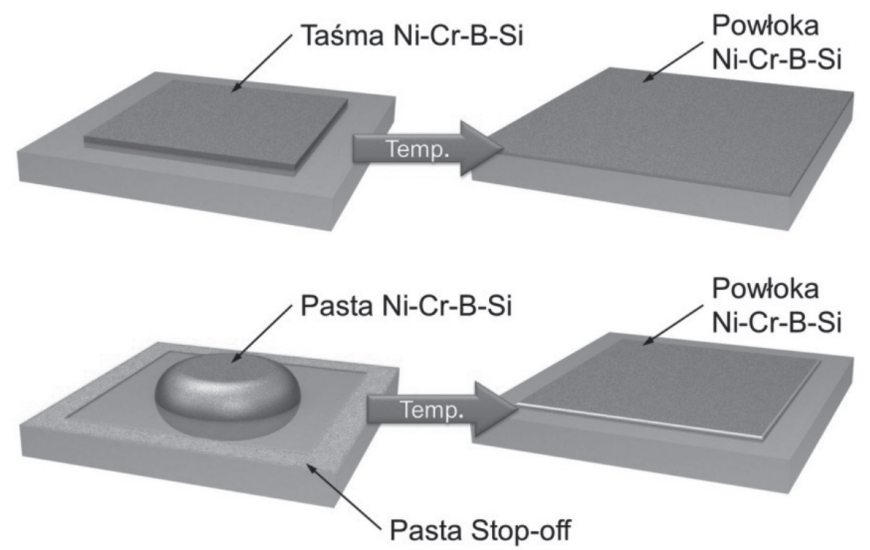

Rys. 1. Schemat natapiania

Fig. 1. The surfacing process scheme

Proces natapiania w piecu próżniowym składa się z trzech etapów. W pierwszym następuje nagrzewanie i topienie materiału powłokowego. Nagrzewanie odbywa się z określoną szybkością, z przystankami temperaturowymi lub bez. Drugi etap obejmuje wygrzewanie

Mgr inż. Adam Kondej - Instytut Mechaniki Precyzyjnej.

Autor korespondencyjny/Corresponding author. adam.kondej@imp.edu.pl 
ciekłego stopu w zadanej temperaturze przez określony czas. W trzecim etapie następuje chłodzenie i krystalizacja ciekłego stopu przy obniżonym ciśnieniu komory roboczej.

Temperatura procesu zależy od temperatury likwidus zastosowanego stopu, np. dla stopów Ni-Cr-B-Si wynosi powyżej $1000{ }^{\circ} \mathrm{C}$. W miejscach fizycznego kontaktu ciekłego stopu z podłożem zachodzi dyfuzja pierwiastków. Wielkość tworzącej się strefy dyfuzyjnej zależy od czasu i temperatury procesu $[4,5]$.

\section{Parametry procesu natapiania}

Jako materiał powłokowy zastosowano stop Ni-Cr-B-Si w postaci pasty - oznaczenie BNi-2, którego skład chemiczny przedstawiono $w$ tablicy I. Stop natapiano na próbki ze stali 42CrMo4. Proces wykonano w laboratoryjnym piecu próżniowym, przy następujących parametrach: temperatura $1075^{\circ} \mathrm{C}$, czas wygrzewania 30 minut, szybkość nagrzewania $15^{\circ} \mathrm{C} / \mathrm{min}$, ciśnienie w komorze roboczej $10^{-3} \mathrm{mbar}$, chłodzenie wolne $-z$ piecem.

Tablica I. Skład chemiczny stopu Ni-Cr-B-Si - pasta BNi-2 [6] Table I. The chemical composition of the Ni-Cr-B-Si alloy - the BNi-2 paste [6]

\begin{tabular}{|c|c|c|c|c|}
\hline \multicolumn{5}{|c|}{ Skład chemiczny [\% wag.] } \\
\hline $\mathrm{Ni}$ & $\mathrm{Cr}$ & $\mathrm{Si}$ & $\mathrm{B}$ & $\mathrm{Fe}$ \\
\hline 82,3 & 7,0 & 4,5 & 3,2 & 3,0 \\
\hline
\end{tabular}

\section{Mikrostruktura natapianej powłoki Ni-Cr-B-Si}

Obrazy mikroskopowe natapianej powłoki Ni-Cr-B-Si przedstawiono na rysunku 2. Powłoka jest wielofazowa, osnowę stanowi roztwór stały na bazie niklu. Wydzielenia borków chromu oraz borków i krzemków niklu umacniają plastyczną osnowę. Połączenie powłoki z podłożem ma charakter dyfuzyjny. W strefie dyfuzji tworzą się fazy, rozrastające się w głąb podłoża, głównie po granicach ziaren, są to najprawdopodobniej borki żelaza. Na powierzchni powłoki obecne są wydzielenia borków chromu o nieregularnym kształcie [3,7].

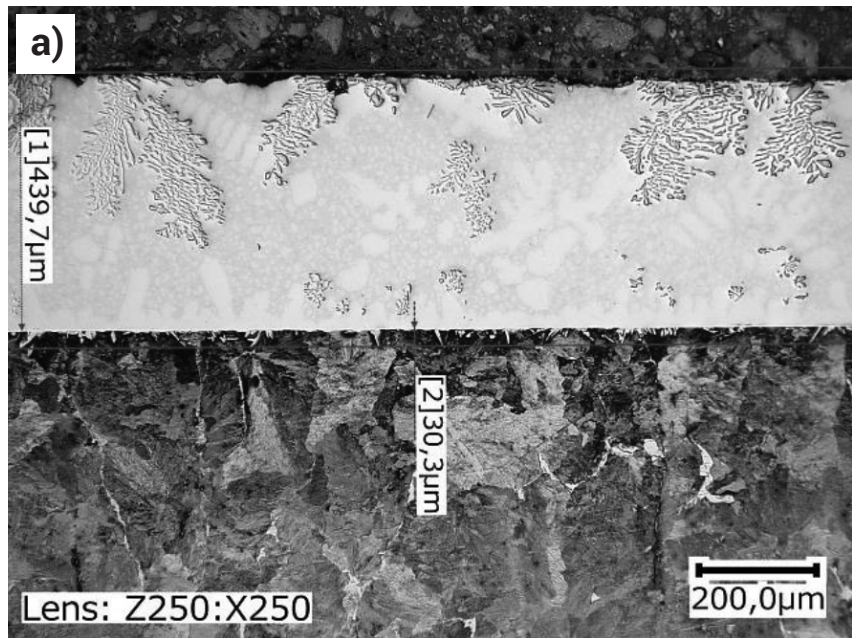

\section{Naddźwiękowe natryskiwanie płomieniowe}

Natryskiwanie cieplne należy do podstawowych metod wytwarzania powłok ochronnych, odpornych na zużycie ścierne, korozję oraz o innych, specjalnych właściwościach. Jedną z metod natryskiwania cieplnego jest naddźwiękowe natryskiwanie płomieniowe (HVOF). W procesie natryskiwania HVOF źródłem ciepła jest płomień powstający ze spalania mieszanki tlenu i gazowego lub płynnego paliwa. Materiał powłokowy w postaci proszku jest dostarczany pneumatycznie przez podajnik do strumienia spalanych gazów. Ziarna proszku przelatując przez płomień, nagrzewają się powyżej temperatury granicy plastyczności. Strumień gazów spalinowych wyrzuca cząstki materiału powłokowego z prędkościami naddźwiękowymi (powyżej $600 \mathrm{~m} / \mathrm{s}$ ) nadając im dużą energię kinetyczną. Krótki czas przebywania w strumieniu gazów ogranicza proces utleniania cząstek proszku i zmian ich składu fazowego. Powłoki natryskane metodą naddźwiękową mają małą porowatość (<1\%), małą zawartość tlenków oraz bardzo dobrą przyczepności do podłoża. Schemat natryskiwania HVOF zamieszczono na rysunku $3[8,9]$.

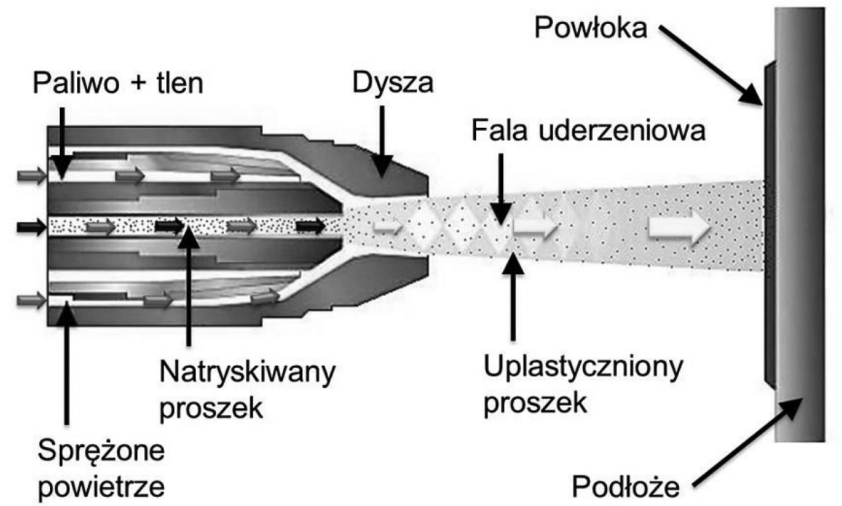

Rys. 3. Schemat natryskiwania HVOF Fig. 3. The HVOF spraying scheme

\section{Parametry procesu natryskiwania HVOF}

Do prób natryskiwania HVOF zastosowano proszek Ni-Cr-B-Si firmy Castolin Eutectic - BoroTec 10009. Skład chemiczny proszku zamieszczono w tablicy II. Bezpośrednio przed natryskiwaniem próbki poddano obróbce strumieniowo-ściernej elektrokorundem nr 14. Natryskiwanie prowadzono w sposób ręczny przy użyciu naddźwiękowego pistoletu płomieniowego firmy AMIL Werkstofftechnologie $\mathrm{GmbH}$

Rys. 2. Obraz mikroskopowy natapianej powłoki Ni-Cr-B-Si: a) zgład, b) powierzchnia powłoki

Fig. 2. The microscopic image of the surfaced Ni-Cr-B-Si coating: a) the metallographic section b) the coating's surface 
Tablica II. Skład chemiczny proszku Ni-Cr-B-Si - Castolin Eutectic BoroTec 10009 [10]

Table II. The chemical composition of the Ni-Cr-B-Si powder - Castolin Eutectic BoroTec 10009 [10]

\begin{tabular}{|c|c|c|c|c|c|c|c|c|}
\hline \multicolumn{10}{|c|}{ Skład chemiczny [\% wag.] } \\
\hline $\mathrm{Ni}$ & $\mathrm{Cr}$ & $\mathrm{Si}$ & $\mathrm{Fe}$ & $\mathrm{B}$ & $\mathrm{C}$ & $\mathrm{O}$ & $\mathrm{P}$ & $\mathrm{S}$ \\
\hline 71,87 & 15,67 & 4,24 & 3,80 & 3,32 & 0,69 & 0,40 & 0,004 & 0,004 \\
\hline
\end{tabular}

(rys. 4) według następujących parametrów: ciśnienie tlenu 0,8 MPa, ciśnienie propanu - 0,4 MPa, ciśnienie sprężonego powietrza 0,55 MPa, odległość pistoletu od powierzchni natryskiwanej $200 \mathrm{~mm}$. Część próbek z natryskanymi powłokami poddano procesowi przetapiania w piecu próżniowym - parametry jak podczas natapiania piecowego.

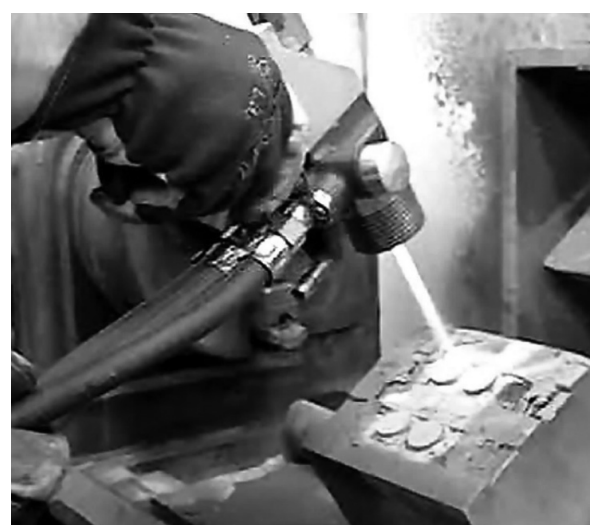

Rys. 4. Proces ręcznego natryskiwania HVOF

Fig. 4. The process of manual HVOF thermal spraying

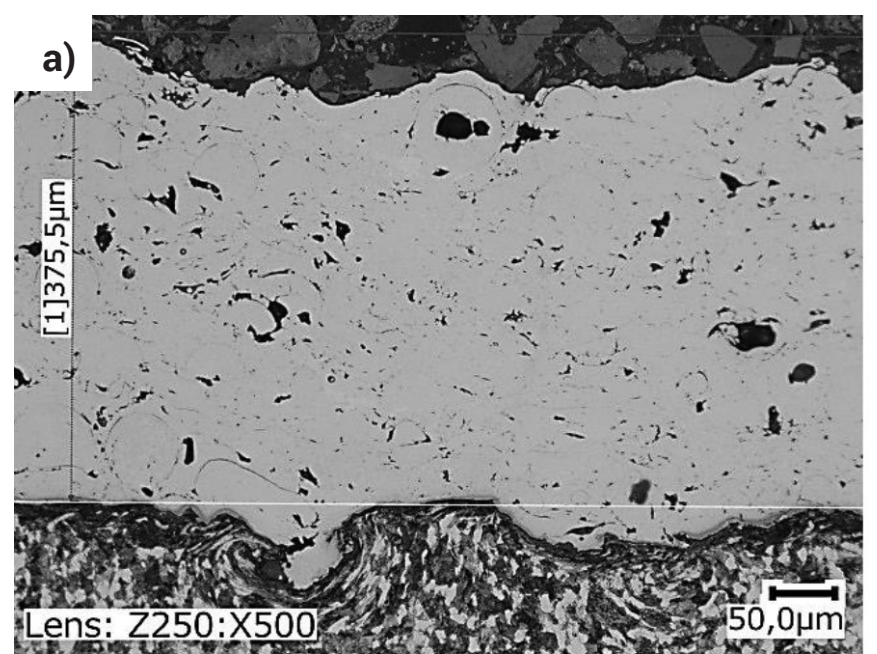

\section{Mikrostruktura natryskanej powłoki Ni-Cr-B-Si}

Obrazy mikroskopowe natryskanej i nieprzetopionej powłoki Ni-Cr-B-Si przedstawiono na rysunku 5. Połączenie powłoki z podłożem ma charakter adhezyjny. W powłoce widoczne są odkształcone plastycznie cząstki natryskanego proszku. W wyniku uderzeń cząstek nastąpiło także odkształcenie plastyczne warstwy wierzchniej podłoża.

Po procesie przetapiania połączenie powłoki z podłożem ma charakter dyfuzyjny. Powłoka uległa całkowitemu przetopieniu - brak odkształconych plastycznie cząstek natryskanego proszku. Mikrostruktura wielofazowej powłoki różni się od powłoki natapianej w piecu próżniowym. Wyraźna różnica dotyczy kształtu wydzieleń wewnątrz powłoki, jak i na jej powierzchni. W powłoce natryskanej i przetopionej wydzielenia mają postać drobnych igieł, gęsto rozmieszczonych w całej objętości powłoki oraz na jej powierzchni. Obrazy mikroskopowe natryskanej i przetopionej powłoki Ni-Cr-B-Si przedstawiono na rysunku 6.

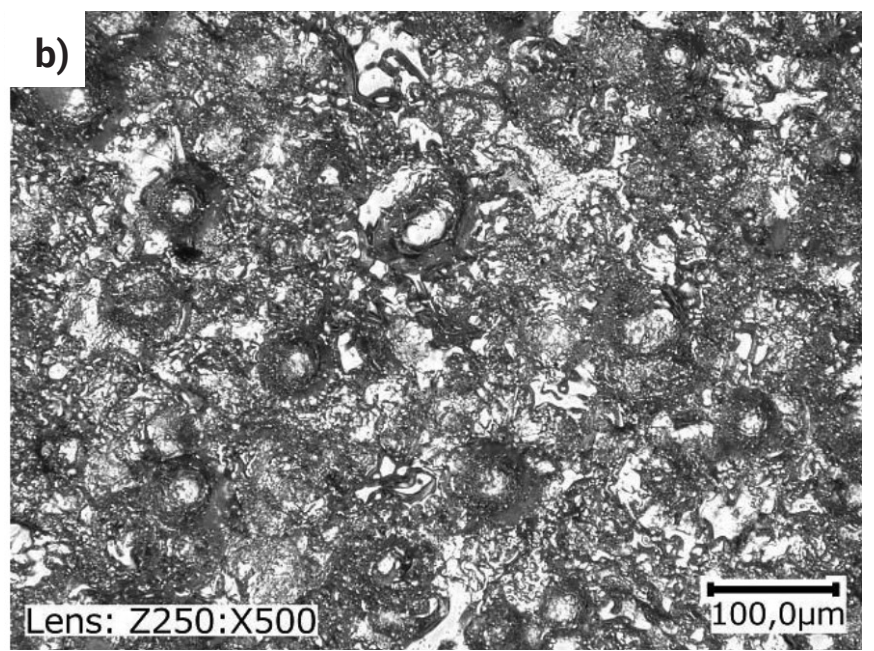

Rys. 5. Obraz mikroskopowy natryskanej powłoki Ni-Cr-B-Si: a) zgład, b) powierzchnia powłoki

Fig. 5. The microscopic image of the thermal sprayed Ni-Cr-B-Si coating: a) the metallographic section b) the coating's surface
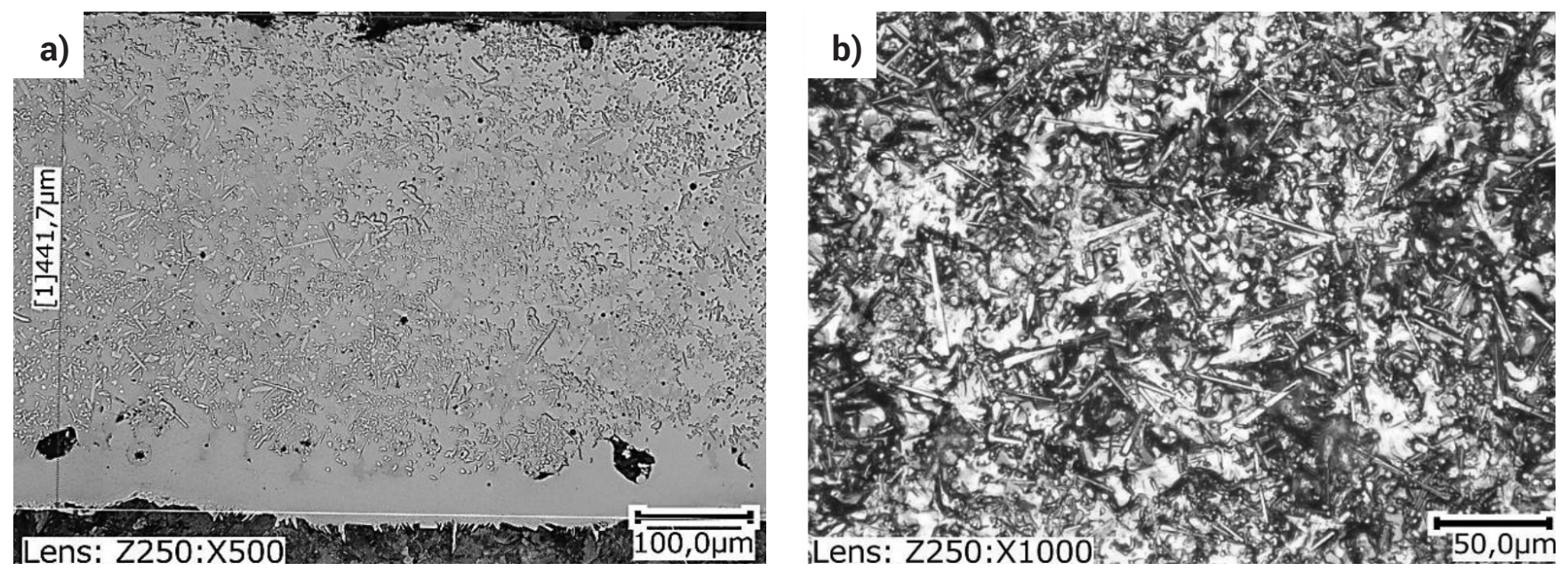

Rys. 6. Obraz mikroskopowy natryskanej i przetopionej powłoki Ni-Cr-B-Si: a) zgład, b) powierzchnia powłoki

Fig. 6. The microscopic image of the thermal sprayed and remelted Ni-Cr-B-Si coating: a) the metallographic section b) the coating's surface 


\section{Pomiary twardości powierzchniowej powłok Ni-Cr-B-Si}

Pomiary twardości wykonano metodą Vickersa przy obciążeniu 5 kG (HV0,5). Twardość mierzono w pięciu miejscach na powierzchni danej powłoki. Do pomiarów wykorzystano automatyczny twardościomierz Struers DuraScan 70. $\mathrm{Na}$ rysunku 7 zamieszczono wykres kolumnowy średnich wartości twardości HV0,5 dla poszczególnych próbek wraz z odchyleniami standardowymi.

Największą twardością powierzchniową charakteryzuje się powłoka natryskana cieplnie i przetapiana w piecu próżniowym (próbka NC+P) - 828 HV0,5. Natryskana powłoka, niepoddana przetapianiu (próbka NC), ma niższą twardość o 45 HV0,5. Natapiana powłoka BNi-2 (próbka NP) charakteryzuje się twardością powierzchniową na poziomie 711 HV0,5. Na powierzchni powłoki BNi-2 występują wydzielenia o wysokiej twardości, wskazania dla tych miejsc przekraczały niekiedy 950 HV0,5. Niklowa osnowa powłoki posiada znacznie niższą twardość. Powłoka jest różnorodna pod względem twardości. Dla tego przypadku otrzymano największe odchylenie standardowe.

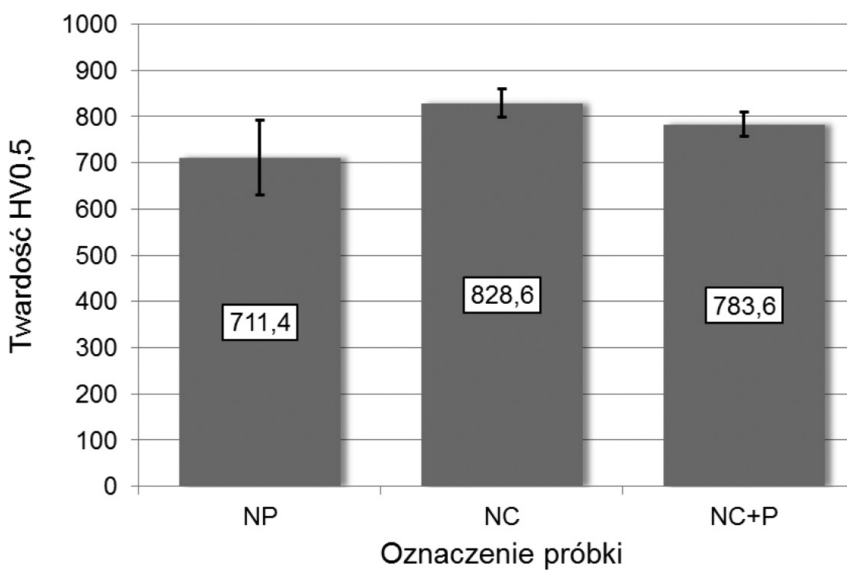

Rys. 7. Średnie wartości twardości powierzchniowej powłok Ni-CrB-Si: NP - powłoka natapiana w piecu próżniowym, NC - powłoka natryskana cieplnie, $\mathrm{NC}+\mathrm{P}$ - powłoka natryskana cieplnie i przetapiana

Fig. 7. The average values of the surface hardness of the Ni-Cr-BSi coatings: NP - surfaced coating, NC - thermal sprayed coating, $\mathrm{NC}+\mathrm{P}$ - surfaced and remelted coating

\section{Podsumowanie}

Natryskiwanie cieplne metodą HVOF pozwala na otrzymywanie powłok Ni-Cr-B-Si. Proces wymaga odpowiedniego przygotowania powierzchni podłoża przez obróbkę strumieniowo-ścierną w celu rozwinięcia powierzchni i zwiększenia przyczepności powłoki z podłożem. Połączenie powłoki z podłożem ma charakter adhezyjny. Powłoki Ni-CrB-Si należą do grupy powłok przetapialnych. Przetapianie natryskanej powłoki powoduję zmianę jej mikrostruktury, zmniejsza porowatość, zwiększa szczelność, aktywuje zjawiska dyfuzyjne, przez co przyczepność powłoki z podłożem jest większa. Zaletą natryskiwania cieplnego jest mała ilość ciepła wprowadzana do podłoża, dzięki czemu jego mikrostruktura nie ulega zmianie.

Alternatywną metodą wytwarzania powłok Ni-Cr-B-Si jest natapianie w piecu próżniowym. Metoda nie wymaga stosowania obróbki strumieniowo-ściernej w celu przygotowania powierzchni pod powłokę. Obecność próżni zapewnia ochronę materiału podłoża oraz stopu przed utlenianiem w trakcie procesu. Wytwarzanie powłoki w piecu próżniowym odbywa się w wysokiej temperaturze, co może powodować niekorzystne zmiany strukturalne w materiale podłoża. Rozrost ziarna ma wpływ na obniżenie wytrzymałości rdzenia, dlatego elementy pracujące przy dużych obciążeniach należy poddać dodatkowo obróbce cieplnej. Rodzaj i parametry obróbki cieplnej dobiera się do gatunku materiału podłoża oraz warunków pracy gotowego elementu. Zastosowanie pieca próżniowego z gazowym chłodzeniem komory roboczej pozwala na przeprowadzenie procesów natapiania i obróbki cieplnej w jednej operacji.

Badania zrealizowano w Instytucie Mechaniki Precyzyjnej w ramach pracy statutowej pt. "Modyfikacja powierzchni stali z wykorzystaniem stopów na bazie metali nieżelaznych".

\section{Literatura}

[1] T. Nastaj: Badanie odporności na zużycie ścierne powłok napawanych stopami na baize niklu. Eksploatacja i Niezawodność, nr 2, s. 49-51, 2003.

[2] O. Knotek, E. Lugscheider: Brazing filler metals based on reacting Ni-Cr-BSi alloys. Welding Research Supplement, p. 314-318, 1976.

[3] A. Kondej, T. Babul, J. Brzozowska: Wybrane właściwości natapianej powłoki Ni-Cr-B-Si. Inżynieria Powierzchni, nr 3, s. 33-38, 2016

[4] T. Babul, A. Kondej: Modyfikacja powierzchni stali przez natapianie pasty BNi-2. Przegląd Spawalnictwa, nr 4, s. 28-32, 2015.

[5] A. Kondej, T. Babul: Struktura wielofazowej powłoki otrzymanej po natapianiu pasty BNi-2 na podłoże stalowe. Inżynieria Powierzchni, nr 3 , s. $10-16,2015$
[6] www.aimtek.com

[7] A. Kondej, T. Babul: Mikrostruktura natapianej powłoki Ni-Cr-B-Si. Przegląd Spawalnictwa, nr 3, s. 23-26, 2016

[8] K. Ferenc: Spawalnictwo. Wydawnictwo WNT, Warszawa, 2013.

[9] W. Milewski, K. Butkiewicz: Wykorzystanie metod HVOF w przemyśle. Inżynieria Powierzchni, nr 3, s. 64-70, 2006.

[10] A. Olbrycht, Sz. Pawlik: Wpływ zawartości kobaltu na właściwości powłok WC-Co natryskiwanych naddźwiękowo. Inżynieria Powierzchni, nr 3, s. $45-53,2016$

[11] www.castolin.com 